\title{
МЕЗОМАСШТАБНЫЕ ВИХРИ В ОЗЕРАХ
}

\begin{abstract}
Кириллин Г.Б.
Leibniz-Institute of Freshwater Ecology and Inland Fisheries (IGB), Müggelseedamm 310, 12587 Berlin Germany, tel.+493064181669, e-mail: kirillin@igb-berlin.de

In lakes with horizontal dimensions less than the internal Rossby deformation radius the mesoscale coherent structures are usually a priori excluded from consideration. Eddies however seem to be a persistent feature of lake dynamics, and represent by this an insightful analogy to oceanic flows. Their importance on lake-wide scales remains unknown.
\end{abstract}

Горизонтальные масштабы большинства озер не превышают нескольких километров, что обычно меньше чем их характерный бароклинный радиус Россби. Таким образом, в отсутствие заметного влияния вращения земли на движение воды, озера считаются свободными от мезомасштабных вращающихся структур. Подробные наблюдения за динамкой озер на суб-синоптических временных масштабах стали проводиться сравнительно недавно и продемонстрировали наличие долгоживущих вихревых структур, близких по характеристикам к атмосферным и океанским синоптичечским вихрям. В данной работе обсуждаются характеристики озерных вихрей и возможные пути их генерации.

Первые детальные наблюдения озерных мезомасштабных вихрей были предприняты в озере Stechlin (Германия) с помощью подповерхностных дрифтеров (поплавков нейтральной плавучести) в 2004-2005 гг. [1]. Вихри были неоднократно прослежены в условиях, предполагающих отсутствие заметного влияния силы Кориолиса, при отношении бароклинного радиуса Россби к характерному горизонтальному масштабу около $3: 1$. В кинематических свойствах вихрей завихренность преобладала над прочими компонентами лагранжевого движения - дивергенцией, сдвигом и растяжением - демонстрируя близкий к твердотельному характер вращения с угловыми скоростями 3 оборота в день. Центроид вихря мог оставаться на месте, но чаще дрейфовал со скоростью около 300 м день под влиянием преобладающей циркуляции. Из многих возможных механизмов генерации таких вихрей наиболее вероятным представляется взаимодействие с неоднороностями дна сейшевых колебаний, на которых аккумулируется большая часть 


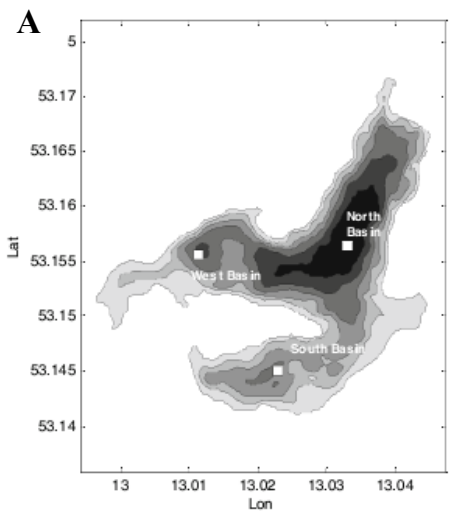

$$
\text { Б } \quad \mathrm{T}=2.46 \mathrm{hrs}
$$
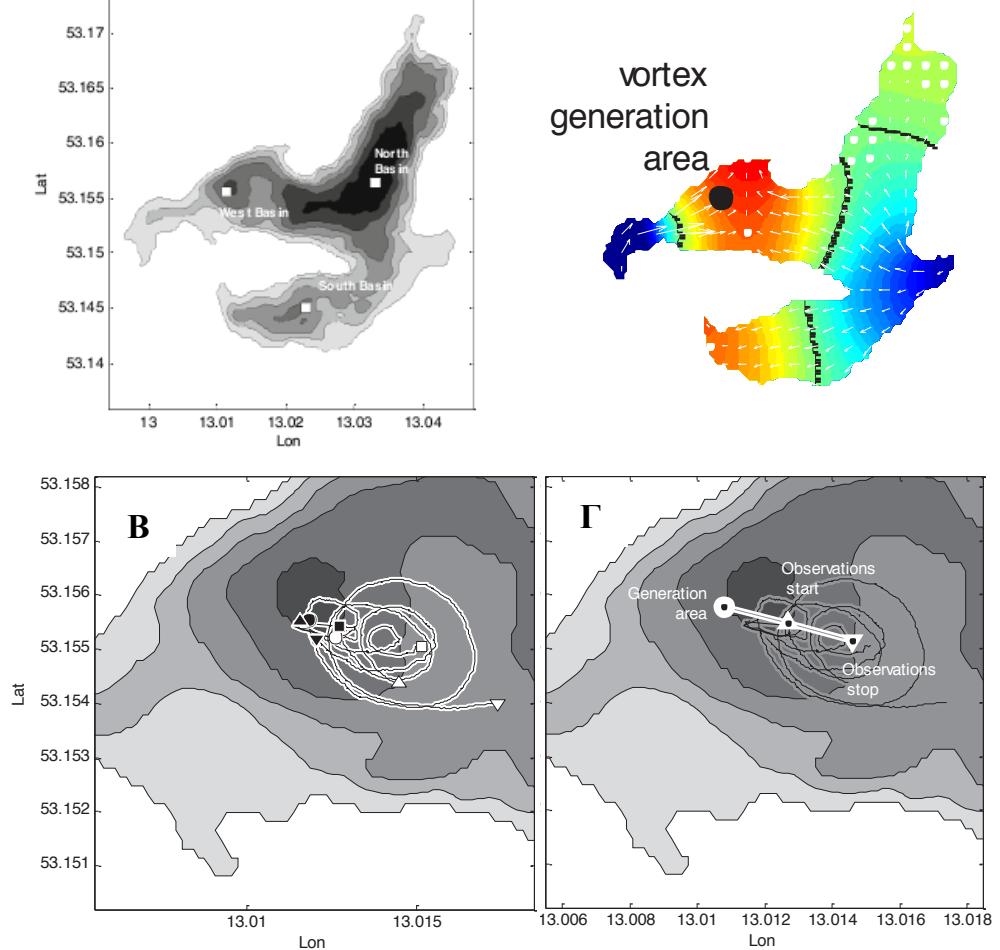

Рис. 1. Озеро Штехлин и траектория одного из наблюденных в нем вихрей: (А) Батиметрическая карта, изобаты через 10 м. (Б) Амплитуды четвертой моды собственных колебаний в условных единицах (цвет) и градиент собственных функций (стрелки), показывающий направление и относительную скорость сейшевых течений. Узловые линии сейши показаны черным. (В) Траектории отдельных дрифтеров. (Г) Траектория поступательного движения вихря.

кинетической энергии в озерах. Данный вывод подтверждается также результатами моделирования, согласно которым вихри возникают при прохождении над резким падением дна одиночных солитоно-подобных внутренних волн (internal bores), либо при генерации сейшевых колебаний высших мод, которые имеют максимум амплидуды вблизи локализованного падения дна (рис. 1). Мультимодальный характер сейшей и неоднородная морфометрия различных озер предполагают, что это взаимодействие может принимать различные формы, будучи 
типичным для большинства озер и внося значительный вклад в массообмен между литоральными (прибрежными) и пелагиальными (центральными) водами.

Особый вид циркуляции в озерах представляет собой динамика озер, покрытых льдом. Оставаясь слабо стратифицированными, озера подо льдом имеют малый бароклинный радиус Россби, так что сила Кориолиса приобретает основное значение в циркуляции, потенциально способствуя образованию стабильных вихрей. Этому также способствует отсутствие ветровых течений. Стабильный циклонический вихрь с характеристиками, близкими к мезомаштабным океанским вихрям, был описан Форрестом и др. [2] в покрытом льдом озере Pavilion (Канада). Вихрь с горизонтальными размерами около 100 м занимал верхний перемешанный слой в центре озера, без видимой связи с неоднородностями дна или повехностными/ грунтовыми притоками. Механизм генерации остался невыясненым, однако важная роль силы Кориолиса в поддержании вращательного движения была очевидна (бароклинный радиус Россби 200 м), и авторы провели аналогию с вихрями, наблюдаемыми под океанским льдом (см., напр., [3]). Дополнитеный шаг к пониманю механизмов возникновения вихрей в пресноводных озерах, покрытых льдом, был сделан в работе [4] по наблюдениям в полярном озере Kilpisjärvi (Финляндия). На поздней стадии ледового периода, прогрев воды в береговых промоинах приводит к конвергентным склоновым течениям и апвеллингу в центральной части озера. Возвратное дивергентное течение при этом уравновешивается Кориолисовым ускорением и приводит к возникновению антициклонической циркуляции. Последняя, в свою очередь, интенсифицируется за счет уменьшения глубины в направлении радиальной компоненты дивергентного течения (рис. 2). Угловая скорость вихря достигала 0.33 оборота в день, что существенно для подледных озерных течений и предполагает интенсивный обмен водными массами между литоралью и пелагиалью. Следовательно, образованию вихрей способствуют общие для всех подледных озер черты, такие как отсутствие ветрового перемешивания и горизонтальные неоднородности поверхностного прогрева и рельефа дна. Общность вихреобразования как характерной черты для озер покрытых льдом, подтверждают наблюдения в Байкале и др. озерах $[5,6]$. Роль вихрей в озерной динамике остается предметом изучения. 


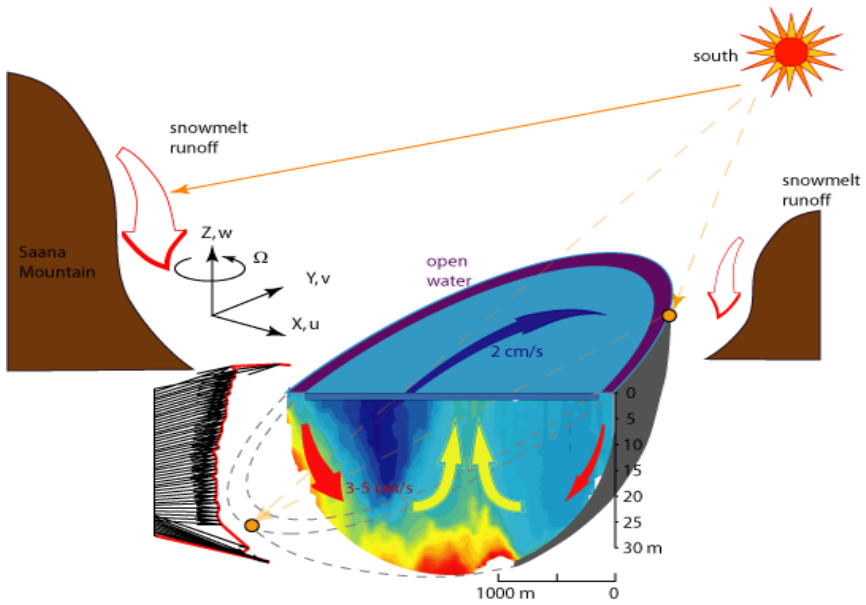

Рис. 2. Схема образования антициклонического вихря при таянии прибрежного льда в озерах. Разрез: температура воды в оз. Kilpisjärvi по шкале $0-4^{\circ} \mathrm{C}$. Стрелки: вертикальный профиль скоростей течения.

\section{ЛИТЕРАТУРА}

1. Kirillin G., Englehardt C., and Golosov S. A mesoscale vortex in a small stratified lake // Environ. Fluid Mech. 2008. Vol. 8. P. 349-366.

2. Forrest A.L., Laval B.E., Pieters R., and Lim D. A cyclonic gyre in an ice-covered lake // Limnol. Oceanogr. 2013. Vol. 58. P. 363-375.

3. Timmermans M.-L.,Toole J., Proshutinsky A., Krishfield R., and Plueddemann A. Eddies in the Canada Basin, Arctic Ocean, observed from ice-tethered profilers // J. Phys. Ocean. 2008. Vol. 38. P. 133-145.

4. Kirillin G.B., Forrest A.L., Graves K.E., Fischer A., Engelhardt C., and Laval B.E. Axisymmetric circulation driven by marginal heating in ice-covered lakes // Geophys. Res. Lett. 2015. Vol. 42. P. 2893-2900.

5. Granin N.G., Kozlov V.V., Tsvetova E.A., and Gnatovsky R.Y. Field studies and some results of numerical modeling of a ring structure on Baikal ice // Doklady Earth Sciences 2015. Vol. 461. P. 316-320

6. Kouraev A.V., Zakharova E.A., Rémy F., Kostianoy A.G., Shimaraev M.N., Hall N.M., \& Suknev A.Y. Giant ice rings on lakes Baikal and Hovsgol: Inventory, associated water structure and potential formation mechanism // Limnol. Oceanogr. 2016. Vol. 61. P. 1001-1014. 